\title{
Sequencing Analysis and Enzyme Activity Assay of SrUGT76G1 Revealed the Mechanism Toward on/off Production of Rebaudioside-A in Stevia Plants
}

Simone Ribeiro Lucho ( $\square$ simonibelmonte@gmail.com )

Universidade Federal de Pelotas

Marcelo do Amaral

Federal University of Pelotas: Universidade Federal de Pelotas

\section{Valmor Bianchi}

Federal University of Pelotas: Universidade Federal de Pelotas

Lorena Almagro

University of Murcia: Universidad de Murcia

\section{Maria Ferrer}

Technical University of Cartagena: Universidad Politecnica de Cartagena

\section{Antonio Calderon}

Technical University of Cartagena: Universidad Politecnica de Cartagena

\section{Eugenia jacira Braga}

Federal University of Pelotas: Universidade Federal de Pelotas

\section{Research Article}

Keywords: Stevia rebaudiana, catalytic function, key amino acids, steviol glycosides, sweetener

Posted Date: October 20th, 2021

DOl: https://doi.org/10.21203/rs.3.rs-987472/v1

License: (a) (i) This work is licensed under a Creative Commons Attribution 4.0 International License. Read Full License 


\section{Abstract}

Stevia plants is known for its ability to synthesize steviol glycosides (SGs), a natural sweetener blend. Stevioside (STEV) and Rebaudioside-A (Reb-A) are the main SGs. However, Reb-A is more palatable than STEV and shows reduced bitter aftertaste. SrUGT76G1 catalyzes the conversion of STEV to Reb-A, improving their organoleptic properties. The better understanding of the structure/activity of SrUGT76G1 would allow shedding light up on on/off production of Reb-A in stevia plants. Thus, we analyzed the STEV and Reb-A content in stevia leaves of plants from Brazil and Spain and did not find detectable levels of Reb-A in Brazilian samples (off production). For this reason, we used a sequencing tool to study at the genetic and structural level the SrUGT76G1 gene. Changes in key amino acid residues in Brazilian samples were found, such as $\mathrm{Leu}_{204} \mathrm{Phe}, \mathrm{Thr}_{284} \mathrm{Leu}$ and $\mathrm{Leu}_{126} \mathrm{lle}$. Leu ${ }_{204}$ Phe mutants can narrow substrate-binding pocket to favor flavonoids recognition and decrease SGs synthesis, while $\mathrm{Thr}_{284}$ is considered key for 1,3-glucosylation of SGs, including Reb-A. These punctual mutations may partly explain the lack of functionality of UGT76G1 enzyme and off production of Reb-A in stevia plants from Brazil. Following this trend, Brazilian samples exhibited a T-to-A substitution, resulting in premature stop codon. As expected, the relative expression of SrUGT76G1 gene showed a higher level in Spanish samples than in Brazilian ones. Collectively, the results presented here show the structure-activity interplay of SrUGT76G1 enzyme and provide new insights on structural features and its role toward Reb-A synthesis.

\section{Introduction}

Stevia rebaudiana Bertoni is a perennial plant of the family Asteraceae, known worldwide by biosynthesizing steviol glycosides (SGs) with extremely sweet properties (Geuns 2003; Lemus-Mondaca et al., 2012; Yadav and Guleria 2012). According to Chughtai et al., (2020) and Ahmad et al., (2020), SGs show a wide range of pharmacological applications, among which stand out anti-diabetic, anti-tumour and protection against cardiovascular diseases. Steviol glycosides share the same backbone structure (steviol), it is a diterpenoid aglycone with multiple glycosyl substitutes attached to C19-carboxylic acid $\left(R_{1}\right)$ and/or C13-hydroxyl $\left(R_{2}\right)$ positions, which result in differences in sweetness (Figure 1). Stevioside (4$13 \% \mathrm{w} / \mathrm{w})$ and rebaudioside- $\mathrm{A}(2-4 \% \mathrm{w} / \mathrm{w})$ are the main responsible for this sweetness (Lemus-Mondaca et al., 2012; Yadav, Guleria 2012), however, rebaudioside-A (Reb-A) is more palatable than stevioside (STEV) and shows reduced bitter aftertaste (Madhav et al., 2012). Thus, both the Reb-A/STEV ratio and the number of glucose moieties in $\mathrm{C}-13$ to that at the $\mathrm{C}-19$ ratio are what determine the degree of sweetness (Yadav, Guleria 2012; Gerwig et al., 2017).

According to Kumar et al., (2012) the biosynthesis of the SGs in stevia plants can be separated into three stages according to the nature of the enzymes involved. First stage wherein geranylgeranyl diphosphate (GGDP) is synthesized from 2-C-methyl-D-erythritol-4-phosphate (MEP) through the so called MEP pathway. Second stage, in which the condensation steps take place, producing kaurenoic acid (KA). In the last stage hydroxylation of KA and glycosylation of steviol catalyzed by UDP (uridine diphosphate)glycosyltransferases (UGTs) (EC 2.4) occurs (Richman et al., 1999, 2005). UGTs are enzymes able to 
catalyze sugar transfer from a donor to an acceptor molecule (Zhang et al., 2020a) what may result in a power sweetener compound (Ullah et al., 2019).

About 68 UGTs have been identified in Stevia rebaudiana (Petit el al., 2020), of these five were elucidated, SrUGT74G1, SrUGT76G1, SrUGT85C2 SrUGT91D2, and SrUGT93E1 (Richman et al., 2005, Wang et al., 2016, Li et al., 2018). The first enzyme to glycosylate Steviol ${ }^{(1)}$ in the C-13 hydroxyl group is SrUGT85C2 producing Steviolmonoside ${ }^{(2)}$. In addition, Steviol ${ }^{(1)}$ also undergoes the action of SrUGT73E1 forming

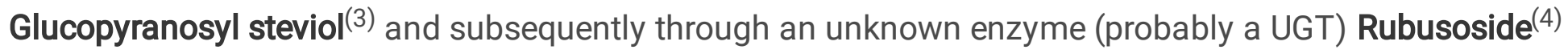
is formed. SrUGT91D2 can catalyze the transformation of Steviolmonoside ${ }^{(2)}$ to Steviolbioside ${ }^{(5)}$, extending the sugar chain and besides, SrUGT91D2 also catalyzes both the conversion of Rubusoside ${ }^{(4)}$ to Stevioside ${ }^{(6)}$ and that of Stevioside ${ }^{(6)}$ to Rebaudioside- $\mathrm{E}^{(8)}$. Stevioside ${ }^{(6)}$ is also synthesized by the action of SrUGT74G1 (which glucosylates the C-19 carboxylic acid position). Rebaudioside-A ${ }^{(7)}$ biosynthesis is the result of the catalytic ability of SrUGT76G1 acting on Stevioside ${ }^{(6)}$. Next, Rebaudioside-A ${ }^{(7)}$ can be transformed into Rebaudioside- ${ }^{(9)}$ and Rebaudioside-M ${ }^{(10)}$, via SrUG91D2 and SrUGT76G1, respectively. SrUGT76G1 also appears to catalyze the conversion of Rebaudioside $A^{(7)}$ to Rebaudioside- $^{(11)}$, and the same enzyme catalyzes Rubusoside ${ }^{(4)}$ to Rebaudioside- ${ }^{(12)}$ and Rebaudioside $\mathbf{Q}^{(13)}$. Further, the formation of Rebaudioside-B ${ }^{(14)}$ seems to derive from the action of SrUGT76G1 on Steviolbioside ${ }^{(5)}$ (see Figure 1) (Richman et al., 1999; Brandle and Telmer, 2007; Wang et al., 2016; Li et al., 2018).

SrUGT76G1 is responsible for converting stevioside to rebaudioside-A (via the C-3 glucosylation of the glucose at the $\mathrm{C}-13$ position) and seems to catalyze at least six more reactions in stevia plants, defining the power sweetness (Ceunen and Geuns, 2013; Liu et al., 2020). Besides, Kim et al., (2019) demonstrated in a recent study, that Dulcoside $A$ can also be transformed to rebaudioside-C under the action of SrUGT76G1. The understanding of the functionality of SrUGT76G1 enzyme in stevia plants and its relationship with the synthesis of rebaudioside-A have already been the focus of some previous studies (Yang et al., 2014, Petit et al., 2019, Kim et al., 2019, Zhang et al., 2019). However, the key amino acid residues that interfere at its structure and catalytic function are not yet fully understood, mainly regarding in stevia plants with on/off capacity of Reb-A production. Thus, to identify possible mutations in key residues of SrUGT76G1 enzyme in stevia plants grown in Brazil (off - Reb-A production) and plants from Spain (on - Reb-A production), sequencing analyses and enzymatic assays would cast light on the genetic and biochemical basis of this production opposite capacity.

\section{Material And Methods}

\subsection{Plant material}

Stevia plants were collected in the Pelotas region, south of Brazil $\left(31^{\circ} 42^{\prime} 43.2^{\prime \prime S} 52^{\circ} 10^{\prime} 28.7^{\prime \prime} \mathrm{W}\right)$. While, the stevia plants cv. Criolla were provided by a local nursery of Spain. In the laboratory, firstly both genotypes were established in vitro and then cultured on a modified MS medium with macronutrients at half- 
strength (Murashige and Skoog 1962), supplemented with casein hydrolysate $\left(250 \mathrm{mg} \mathrm{L}^{-1}\right)$, sucrose (30 $\left.\mathrm{g} \mathrm{L}^{-1}\right)$ and agar $\left(8 \mathrm{~g} \mathrm{~L}^{-1}\right)$ at $\mathrm{pH}$ 5.8. Plant materials were incubated under a 12-h photoperiod, with a photosynthetic photon flux density of $75 \mu \mathrm{mol} \mathrm{m} \mathrm{m}^{-2} \mathrm{~s}^{-1}$ and a $25^{\circ} \mathrm{C}$ (day) $/ 18^{\circ} \mathrm{C}$ (night) thermoperiod. Leaf samples from these plants (Brazil and Spain) were frozen in liquid nitrogen immediately after sampling for further biochemical and molecular analyses.

\subsection{Steviol glycosides extraction and HPLC measurements}

The extraction, identification and quantification of steviol glycosides were performed according to Lucho et al., (2019b). Chromatograms were obtained at $210 \mathrm{~nm}$ following the procedure described in JECFA (2010). Three analytical replicates were performed. Stevioside and Rebaudioside-A contents were expressed as mg equivalents of rebaudioside-A per gram dry weight.

\subsection{RNA extraction, cDNA preparation, and RT-qPCR analysis}

The total RNA was extracted from $100 \mathrm{mg}$ of young leaves (second or third node from the top) of stevia from Brazil and Spain according to the manufacturer's protocol (Plant RNA Reagent Purilink ${ }^{\circledR}$ USA). The quantity and purity of the RNA were determined using a NanoDrop ND-1000 and the quality and integrity of the RNA verified by electrophoresis on $1.0 \%$ agarose gel. Intact RNA was used to CDNA synthesis using the RT-PCR Kit (Invitrogen $®-18080093$, USA). The RT-qPCR reactions were performed in a Bio-Rad CFX Real-Time Thermocycler, USA. Relative quantification by RT-qPCR was performed in a $10 \mu \mathrm{L}$ volume containing: $1 \mu \mathrm{L}$ of cDNA, $5 \mu \mathrm{L}$ of $2 \times$ SensiFAST SYPBR ${ }^{\circledR}$ No-ROX mix, $0.5 \mu \mathrm{L}$ of each primer, and $3 \mu \mathrm{L}$ of $\mathrm{H}_{2} \mathrm{O}$. The primers used in this study are described in supplementary material - Table 1. ACT and UBQ genes were used as an internal control to normalized data according to Lucho et al., (2018b) and Abdelsalam et al., (2019). The relative quantification was performed by comparative values of $2^{-\triangle \triangle C T}$, where $\triangle \triangle C T=$ (CT of the treated sample - CT of the ACT mean) - (Control sample CT - CT of the ACT mean), according to the method Livak and Schmittgen (2001). Three technical repetitions were performed for each biological repetition. The PCR reactions were performed in triplicate in each of the genotypes.

Table 1

Steviol glycosides content (expressed as mg eq.

Rebaudioside-A g ${ }^{-1}$ DW) in extracts from Stevia rebaudiana Bertoni. Different uppercase letters within a line indicate differences among samples. A t-test at $p<0.05$ was applied to determine significant differences in content. Means \pm SE. Three separate experiments in three replicates were performed. *nd not detected.

\begin{tabular}{|lll|}
\hline Steviol glycosides & Brazil & Spain \\
\hline Stevioside & $18.95 \pm 0.41 \mathrm{~B}$ & $27.62 \pm 4.59 \mathrm{~A}$ \\
\hline Rebaudioside-A & $\mathrm{nd}{ }^{\star} \mathrm{B}$ & $9.74 \pm 2.09 \mathrm{~A}$ \\
\hline
\end{tabular}




\subsection{Extraction and enzymatic activity assay of SrUGT76G1}

Extraction of UGTs was carried out according to Yang et al., (2014) with some minor modifications. Leaf samples (corresponding to about $1.3 \mathrm{~g}$ fresh weight) were homogenized in the presence of $10 \mathrm{~mL} 50 \mathrm{mM}$ Tris- $\mathrm{HCl}$ buffer, $\mathrm{pH}$ 7.0, containing $0.4 \mathrm{mM}$ sucrose and $2 \mathrm{mM}$ 2-mercaptoethanol (extraction buffer). Homogenates were incubated for $30 \mathrm{~min}$ at $4^{\circ} \mathrm{C}$ in the dark and then centrifuged at $15,000 \times \mathrm{g}_{\max }$. Supernatants were brought to $30 \%$ saturation $\left(\mathrm{NH}_{4}\right)_{2} \mathrm{SO}_{4}$ by addition of the solid salt and incubated with slow stirring for $1 \mathrm{~h}$. Then, samples were centrifuged (8,000 $\left.\times \mathrm{g}_{\max }, 10 \mathrm{~min}\right)$ and solid $\left(\mathrm{NH}_{4}\right)_{2} \mathrm{SO}_{4}$ was added to the supernatants up to $80 \%$ saturation. After incubation and subsequent centrifugation under the conditions described above, precipitates obtained were dissolved in $10 \mathrm{ml}$ of extraction buffer and stored at $-20^{\circ} \mathrm{C}$ until use (within one week). Enzymatic conversion of stevioside to rebaudioside-A was checked in reaction media composed of Tris- $\mathrm{HCl} 100 \mathrm{mM}(\mathrm{pH} 6.8), 5 \mathrm{mM} \mathrm{MgCl}_{2}, 1 \mathrm{mM} \mathrm{KCl}, 0.1 \mathrm{mM}$ stevioside, $1 \mathrm{mM}$ UDP-glucose, $0.1 \mathrm{U} \mathrm{mL}^{-1}$ recombinant bovine intestine phosphatase (rAPid Alkaline Phosphatase, Merck), and $100 \mu \mathrm{L}$ protein fraction. Reaction media ( $350 \mu \mathrm{L}$ final volume) were incubated for $2 \mathrm{~h}$ at $30^{\circ} \mathrm{C}$ using a thermoblock and reactions were subsequently stopped by addition of $250 \mu \mathrm{L}$ of $\mathrm{n}$ butanol. After $15 \mathrm{~min}$ of incubation, reaction media were centrifuged at $15,000 \times \mathrm{g}_{\max }$ for $10 \mathrm{~min}$ and butanol phases collected for further chromatographic analyses carried out as described above.

\subsection{PCR conditions, sequencing of PCR amplification products and analysis in silico}

First-strand CDNA was used for PCR. The PCR reaction was performed in a $30 \mu$ reaction mixture containing $5 \mu \mathrm{l} 100 \mathrm{ng} / \mu \mathrm{l}$ cDNA, $2.5 \mu \mathrm{l}$ of each primer at $10 \mathrm{mM}$ concentration, $10 \mu \mathrm{l}(10 \mathrm{x})$ PCR Buffer, $4 \mu \mathrm{l}$ $50 \mathrm{mM} \mathrm{MgCl} 2,1 \mu \mathrm{l} 2.5 \mathrm{mM}$ dNTP, $0.5 \mu \mathrm{l} \mathrm{Taq} \mathrm{DNA} \mathrm{polymerase} \mathrm{(Invitrogen}{ }^{\circledR}$ ), under the following conditions: sample renaturation for $2 \mathrm{~min}$ at $50^{\circ} \mathrm{C}$ and activation of the Taq Polymerase enzyme for 5 min at $95^{\circ} \mathrm{C}$. Subsequently, 40 cycles were carried out, each cycle consisting in three stages $\left(94^{\circ} \mathrm{C}\right.$ for $40 \mathrm{~s}, 55^{\circ} \mathrm{C}$ for $40 \mathrm{~s}$ and $72{ }^{\circ} \mathrm{C}$ for $2 \mathrm{~min}$ ) and finally a last stage at $72{ }^{\circ} \mathrm{C}$ for $10 \mathrm{~min}$ was applied. The SrUGT76G1 gene was amplified using the following primers F1: AACGTCAGTCAAACCCAATG and R1: CTCACATAACCAACAACCATCC (product size: $1.436 \mathrm{bp}$ ). After performing the PCR, the CDNA amplification products (bands) were extracted, purified and directly sequenced in Applied Biosystems 3500 Genetic Analyzer by the automated Sanger method. The analyzes were carried out in the Structural Genomics Laboratory (Federal University of Pelotas) using Gene JET PCR Purification kit from Thermo Scientific $\circledast$ and the concentrations standardized to $50 \mathrm{ng} \mu \mathrm{L}^{-1}$. The primers $(10 \mu \mathrm{M})$ used were as described above. The sequencing results were analyzed using Bioedit Sequence Alignment Editor Program (Hall, 1999). Sequence alignment was done using Clustal Omega online (ClustalW) and compared with the sequences deposited in the National Center for Biotechnology Information (NCBI) database. The secondary and tertiary structure of the proteins were predicted by PSIPRED (Buchan et al., 2010; Jones, 1999) and SWISS-MODEL (Arnold et al., 2006).

\subsection{Phylogenetic analysis of UGT76G1}


The amino acids sequences of UGT76G1 homologous proteins were obtained from GenBank NCBI and subjected to phylogenetic analysis based on the neighbor-joining method with bootstrap values $(1,000$ replicates). The optimal tree with the sum of branch length $=20.08921714$ is shown. The evolutionary distances were computed using the Maximum Composite Likelihood method (Tamura et al., 2004) and they are in the units of the number of base substitutions per site. The proportion of sites where at least one unambiguous base is present in at least one sequence for each descendent clade is shown next to each internal node in the tree. All ambiguous positions were removed for each sequence pair (pairwise deletion option). Phylogenetic analysis was done using MEGA X: Molecular Evolutionary Genetics Analysis (Kumar et al., 2018). The dendrogram was done and show the relatedness and the genetic diversity of SrUGT76G1 (Brazil and Spain) with UGT76G1 (stevia lines and two other species) and others UGTs. The sequence of SrUGT76G1 gene from Brazil and Spain was deposited in NCBI GenBank under number MZ781502 and MZ781503, respectively.

\subsection{Statistical analysis}

The results of gene expression and steviol glycosides content correspond to the mean \pm standard deviation. The results were subjected to analysis of variance and when significant, a t-test at $p<0.05$ was applied, using R software.

\section{Results And Discussion}

\subsection{HPLC Analysis}

The stevioside and rebaudioside-A contents were determined by HPLC and the results are shown in Table 1. There were undetectable levels of Reb-A in Brazil stevia plants (off - Reb-A production), on the other hand, stevia plants (cv. Criolla) from Spain produce Reb-A (on - Reb-A production). We also observed a variation on stevioside content among the genotypes, with stevia plants from Spain showing the highest mean values (27.62 $\pm 4.59 \mathrm{mg}$ Reb-A eq. $\mathrm{g}^{-1} \mathrm{DW}$ ). Previous studies on stevia plants grown in Brazil already have shown low or no content of Reb-A (Lucho et al., 2018a, 2021). Likewise, Bayraktar et al., (2016) also did not detect Reb-A in stevia plants propagated in vitro, except when these plants were cultured in WPM medium supplemented with $0.5 \mathrm{~g} \mathrm{~L}^{-1}$ of alginate. Regarding variations in the Stev/Reb rate, Saifi et al., (2019) reported that wild type varieties of stevia showed a higher concentration of stevioside than that of Reb-A. Moreover, Abdelsalam et al., (2019) suggested that increase in stevioside content may be associated with altitude (high) and temperature (low). Above all, these variations in composition are partially caused by genetic variability (Ceunem and Geuns 2013). In fact, stevia plants produce a wide array of steviol glycosides, but the regulatory mechanisms of their synthesis are not well understood. Therefore, studies involving the expression of SGs biosynthesis-related key genes, enzymatic activity, and proteins structure can help in that understanding.

\subsection{Expression-level change of SGs biosynthesis-related key genes}


The Reb-A synthesis is markedly influenced by SrUGT76G1. In this sense, evaluating the expression level of SrUGT76G1 gene in stevia plants with opposite Reb-A production capacities is a first step in the identification of key factors that control the on/off production behavior of stevia plants with respect to Reb-A. Not surprisingly, our results showed SrUGT76G1 gene expression was significantly higher in Spanish samples (about to 3.0 fold) than the Brazilian samples (Table 2). These results are in line with those obtained from HPLC analyses. The relationship between increased gene expression (SrUGT76G1 gene) and product (Reb-A synthesis) was evidenced in a previous study (Lucho et al., 2019b). Regarding the expression levels of SrUGT74G1 gene, the values were similar in both samples (Brazilian and Spanish).

Table 2

Relative quantification (RQ) of SrUGT74G1 and SrUGT76G1 genes in stevia plants from

Spain and Brazil using RT-qPCR. Different uppercase letters within a line indicate differences among samples. A t-test at $p<$ 0.05 was applied to determine significant differences in gene expression. Means $\pm \mathrm{SE}$.

\begin{tabular}{|lll|}
\hline Gene & Brazil & Spain \\
\hline SrUGT74G1 & $1.00 \pm 0.00 \mathrm{~A}$ & $0.94 \pm 0.04 \mathrm{~A}$ \\
\hline SrUGT76G1 & $1.00 \pm 0.00 \mathrm{~B}$ & $2.99 \pm 0.01 \mathrm{~A}$ \\
\hline
\end{tabular}

\subsection{UGT76G1 enzymatic activity}

The non-functionality of SrUGT76G1 in stevia plants from Brazil was confirmed by enzymatic assays (Figure 2). Neither crude nor partially purified protein fractions from Brazil plants were capable to convert STEV into Reb-A, as judging by the absence of the peak corresponding to the latter in the chromatograms of reaction media (Figure 2A). In contrast, protein fractions from Spanish samples were able to carry out a partial transformation of STEV under the assay conditions, pointing to a functional UGT76G1 protein (Figure 2B). This assay showed the differences between the genotypes in relation to the catalytic activity of SrUGT76G1 enzyme, however it remains to be seen what may be causing this inefficiency in samples from Brazil.

\subsection{SrUGT76G1 amplified by PCR}

The discovery of possible mutations in SrUGT76G1 gene may help to elucidate the mechanism behind the on/off Reb-A production in the leaves of some stevia genotypes, including those grown in Brazil. For this reason, we utilized the sequencing analyses as a tool to study the possible mutations (genomic DNA and $m R N A$ ) in SrUGT76G1. Sequence analysis was done on Brazilian and Spanish samples and compared to cDNA sequence of SrUGT76G1 deposited in NCBI (AY345974.1), namely Reference. An amplicon was obtained from DNA and cDNA at around $1.5 \mathrm{~kb}$, corresponding to the coding sequence of SrUGT76G1 (Supplementary material - Figure 1). 


\subsection{Amino acid, and secondary and tertiary structure modifications}

In the current study, Spanish sample of stevia showed 458 amino acids, while Brazilian one 299 (Figure 3). Besides, the secondary structure of SrUGT76G1 evidenced 13, 23 and 20 helices in Brazilian, Spanish and reference samples (GenBank accession no. AAR06912.1), respectively. In the cases of Spanish and Reference, pretty much covered the same number of amino acids (200 and 201), on the other hand Brazilian samples covering 114 amino acids out of 299. Overall, these helices cover about $42 \%$ of amino acids of each sequence/sample (Figure 3). Madhav et al., (2012) reported the secondary structure of glycosyltransferases in stevia plants, with 19 helices covering 191 amino acids (41.8\%). This percentage is close to the amino acid coverage observed in this study. Moreover, the number of putative domain boundary remains the same in the evaluated samples, however in Brazilian samples it occurs in the amino acid Phe ${ }_{150}$, while in the others in the amino acid $\mathrm{Gln}_{270}$ (Supplementary material - Figure 2). Another marked difference in the Brazilian samples is related to seven-strand formation, while reference and Spanish ones form 12 and 11, respectively.

According to results, in Brazilian samples there are three insertions and two deletions in relation to the others. In addition, Brazilian samples exhibited a T-to-A substitution at position 299 (leucina amino acid), resulting in a premature stop codon at position 896 of the mRNA (p.896L>x) (Figure 4). In an earlier study, Yang et al., (2014) also discovered a nonsense mutation (premature stop codon) in the SrUGT76G1 gene, resulting in a protein with altered spatial structure and consequently very low levels of Reb-A. Recently, Zhang et al., (2019) identified five stevia genotypes (N01-N05) that accumulated different amounts of SGs because of some mutations (base substitutions, single nucleotide polymorphisms, and amino acid substitutions/insertions) in the SrUGT76G1 gene.

The comparison of the amino acid sequences among Reference/Spanish, Reference/Brazilian and Brazilian/Spanish samples unveil that the similarity between Reference/Spanish ones were higher than $97 \%$. On the hand, in Reference/Brazilian samples this similarity decay to $58 \%$, as expected (Supplementary material - Table 2). Coupled with this, in samples from plants grown in Spain, six amino acid changes were observed in relation to the reference, while in Brazilian plants this number rises to 101 amino acids (Figure 4). According to Petit et al., (2019), most of the time, substitution of one amino acid may be prejudicing the recognition of substrates and regioselectivity, leading to catalytic activity reduction of SrUGT76G1.

In a recent study, Liu et al., (2020) showed that residues $\mathrm{Gly}_{87}, \mathrm{PrO}_{91}, \mathrm{ll}_{199}$ and $\mathrm{Leu}_{204}$ define diterpenoids/flavonoid glycosylation, as well as amino acids Leu $85, \mathrm{Met}_{88}, \mathrm{Il}_{90}, \mathrm{Il}_{199}, \mathrm{Leu}_{200}$, and $\mathrm{Il}_{203}$ mutations likely interfere in the substrate preference. Besides, Yang et al., (2019) reported that Reb A and Rubu complexes sites in hydrophobic pocket formed by Leu ${ }_{85}, \operatorname{Met}_{88}, I l e_{90}, A_{s n_{196}}, \operatorname{lle}_{199}, \operatorname{Leu}_{200}$, and $\| l_{203}$. Among these amino acids, Brazilian samples showed mutations in the $\|_{1}{ }_{199}$ Lys, $\mathrm{Leu}_{200} \mathrm{Arg}$ and $\mathrm{Leu}_{204} \mathrm{Phe}$ (Figure 4). In accordance with these authors, changes of $\mathrm{Leu}_{204} \mathrm{Phe}$ can narrow substrate- 
binding pocket to favors flavonoids recognition. Likewise, $\mathrm{Leu}_{204}$ Phe mutants decreased steviol glycosides synthesis (Liu et al., 2020). In addition, other mutations were observed in Brazilian stevia plants, such as $\mathrm{Thr}_{284} \mathrm{Leu}$. $\mathrm{Thr}_{284}$ is considered key for 1,3-glucosylation of SGs, including RebaudiosideA (Olsson et al., 2016; Liu et al., 2020). These punctual mutations may partly explain the low/undetectable production of Rebaudioside-A by plants stevia grown in Brazil (Table 1).

Another important substitution ( $\mathrm{Phe}_{281}$ into a Leu and Gly 282 into a Val) of amino acids were observed in stevia plants from Brazil (Figure 4). According to Olsson et al., (2016) $\mathrm{Phe}_{281}$ and $\mathrm{Gly}_{282}$ form part of the hydrophobic core in the $\mathrm{C}$-terminal domain. For this reason they are considered important. Moreover, Brazilian samples showed replacement of the $\mathrm{Leu}_{126}$ to lle. Lee et al., (2019) recently suggested that $\mathrm{Leu}_{126}$ lle mutations resulted in 750-fold decrease in catalytic function of SrUGT76G1. Change of amino acid residues and activity reduction were also observed in other SrUGTs, i.e., SrUGT91D2 (Zhang et al., 2021). Conversely, some amino acids were common in the evaluated samples, such as $\mathrm{His}_{25}$ and $\mathrm{Asp}_{124}$. $\mathrm{His}_{25}$ is a common in the active site of all SrUGTs, as well as Asp $_{124}$ (Madhav et al., 2012). In accordance with these authors, histidine-aspartate interacts to forming a hydrogen bond that provides more stability and functionally to SrUGTs. Besides, $\mathrm{His}_{25}$ and $\mathrm{Asp}_{124}$ form a conserved catalytic dyad and appear to be responsible for transferring the sugar from the donor molecule to the acceptor substrate (Olsson et al., 2016, Yang et al., 2019).

Overall, all glycosyltransferases of Stevia rebaudiana (SrUGTs) showed the presence of Val74 (Madhav et al., 2012), while that in SrUGT76G1 is Glu74. The sequence comparison of SrUGT76G1 showed this replacement in Reference and Spanish samples, but not in Brazilian sample that like the other SrUGTs showed Val74. Other amino acid residues that have gained prominence and have been recently target for the production of next-generation sugars are $\mathrm{Thr}_{146}$ and $\mathrm{His}_{155}$, both are present in the evaluated samples. With regard to $\mathrm{His}_{155}$, Liu et al., (2020) showed that substitutions of this amino acid (into Arg, Trp and Ala) result in decreased production of stevioside. The absence of this mutation may partly justify the production of stevioside (Table 1) in both samples of stevia plants (Brazilian and Spanish). Still in relation to these two amino acids, Olsson et al., (2016) showed reduction of unwanted products and increased contents of Reb A and Reb M in variants of UGT76G1 such as Thr $_{146} \mathrm{Gly}_{\text {ly }}$ and $\mathrm{His}_{155} \mathrm{Leu}$.

According to Lee et al., (2019) residues $\operatorname{Thr}_{146}, \operatorname{Ser}_{157}, \operatorname{Trp}_{359}, \mathrm{Asp}_{380}$, and $\mathrm{Gln}_{381}$ are considered critical for positioning the glucosyl group in SrUGT76G1. Besides, some of these amino acids ( $\operatorname{Trp}_{359}, \mathrm{Asp}_{380}$, and $\mathrm{Gl}_{381}$ ) are part of the PSPG (putative secondary plant glycosyltransferase) sequence motif found in all the plant UGTs. Amino acid changes (substitution, insertion and deletion) in PSPG box and other sites are reflected in catalysis efficiency and protein structure (secondary and tertiary), as shown in Figure 3 and 5 , where Brazilian samples have a very different conformation in relation to Reference and Spanish ones.

The composition of SGs, as well as their contents are the focus of many researches and several efforts are geared towards production of larger quantities (Yücesan et al., 2016; Kim et al., 2019, Saifi et al., 
2019). However, the understanding of the genetic regulation (transcriptional, post-transcriptional, and post-translational) of SGs biosynthesis pathway, mainly regarding the synthesis of the third-generation sweeteners (Reb-A, D, M, I and Q) is largely unknown. Therefore, if we want to understand/unveil the aspects that influence in this regulation, it is essential to expand studies. In this sense, some strategies have been explored and shown great progress, such as specific miRNA and transcription factors (TFs) discoveries.

Concerning the miRNA in stevia plants, Saifi et al., (2019) demonstrated that miRStv_11 up-regulated SrKAH, whereas miR319g showed the repressive action on SrKO, SrKS and SrUGT85C2 genes which results in low SGs accumulation. This study also co-expressed anti-miR319g and miRStv_11 in leaf and triggers an enhancement of expression of four genes (SrKO, SrKS, SrUGT85C2 and SrKAH) and, consequently, noticed a gain in SGs content. Besides, it was firstly reported that WRKY, MYB, bHLH, and NAC TFs may participate in the regulation of secondary metabolites in stevia (Singh et al., 2017). In a recent study, Zhang et al., (2020b) showed that the SrWRKY71 TFs represses the gene expression of SrUGT76G1 in callus of stevia. These results suggested that SrWRKY71 is an upstream regulator of the SGs biosynthesis in stevia.

\subsection{Phylogenetic analyses}

Phylogenetic studies with public accessions of the SrUGT76G1 gene, Brazilian and Spanish samples, and two other species (Helianthus annuus and Lobelia erinus) were performed and the results are showed trough two phylogenetic trees (Figure 6). Overall, the dendrogram from neighbor-joining method separated 10 accessions into two main Clusters. In the Cluster I are included SrUGT76G1 (Brazilian and Spanish), reference sequence (AY345974.1) and others and the Cluster II consisted of L. erinus/ $H$. annuus (Figure 6A). These observations hold when we compare the amino acid sequences of SrUGT76G1 with all the UGTs previously identified in stevia (Figure 6B). This similarity in results can be a common ancestor for reference, Spanish and Brazilian samples.

Overall, this paper reported the relationship among - steviol glycosides profile - on/off Reb-A production SrUGT76G1 gene expression level - SrUGT76G1 activity - key amino acid residues - protein structure, and offers a genetic basis to plant breeders to get the best use of the 'sweetleaf'. Taken together, results support the prominent global role of SrUGT76G1 in Reb-A and other SGs synthesis.

\section{Conclusion}

Biochemical and molecular characterization of SrUGT76G1 enzyme was performed with based in on/off production of Reb-A in stevia plants from Spain/Brazil, respectively. The change in specific residues of key amino acids and the stop premature codon negatively affected the structure and catalytic function of SrUGT76G1 in Brazilian samples. Such efforts provided additional insight into functionality of SrUGT76G1 in genotypes of stevia with opposite production capacity of Reb-A. Besides, this study provides a basis for generating stevia plants with particular SGs content and composition, including those of the third-generation sweeteners (Reb-A, D, M, I and Q). 


\section{Abbreviations}

GGDP: Geranylgeranyl diphosphate

KAH: Kaurenoic acid

MEP: 2-C-methyl-D-erythritol-4 phosphate

NCBI: National Center for Biotechnology Information

PSPG: Plant secondary product glycosyltransferase motif

Reb-A: rebaudioside-A

Reb-B: rebaudioside-B

Reb-D: rebaudioside-D

Reb-E: rebaudioside-E

Reb-G: rebaudioside-G

Reb-l: rebaudioside-I

Reb-M: rebaudioside-M

Reb-Q: rebaudioside-Q

STEV: stevioside

SGs: steviol glycosides

UGT: uridine-diphosphate glycosyltransferase

SrUGT: uridine-diphosphate glycosyltransferase in Stevia rebaudiana

UGT73E1: UDP glucosyltransferase-73E1

UGT74G1: UDP glucosyltransferase-74G1

UGT76G1: UDP glucosyltransferase-76G1

UGT85C2: UDP glucosyltransferase-85C2

UGT91D2: UDP glucosyltransferase-91D2

\section{Declarations}


Acknowledgements:

The authors gratefully acknowledge the CNPq (Conselho Nacional de Desenvolvimento Cientifíco e Tecnológico) for their financial support and research fellowship EJBB and VJB, as well as the FAPERGS (Fundação de Amparo à Pesquisa do Estado do Rio Grande do Sul). This study was financed in part by CAPES (Coordenação de Aperfeiçoamento de Pessoal de Nível Superior-Brasil-Finance Code 001. We are also grateful to the Structural Genomics Laboratory belonging to the Technological Development Center (CDTec) of the Federal University of Pelotas (UFPEL). This work was partially carried out at IBV (Instituto de Biotecnología Vegetal), UPCT (Spain).

\section{Author contributions:}

Conceived and designed the experiments: SRL, AAC and EJBB. Performed the experiments: SRL, AAC, LA and MNA. Analyzed the data: SRL, AAC and MNA. Wrote the paper: SRL and AAC. Corrected the manuscript: MAF, AAC, VJB and EJBB.

\section{Conflict of Interest:}

The authors declare that they have no conflict of interest.

\section{References}

1. Abdelsalam NR, Botros WA, Khaled AE, Ghonema MA, Hussein SG, Ali HM, Elshikh MS (2019) Comparison of uridine diphosphate-glycosyltransferase UGT76G1 genes from some varieties of Stevia rebaudiana Bertoni. Sci Rep 9:8559. https://doi.org/10.1038/s41598-019-44989-4

2. Ahmad J, Khan I, Blundell R, Azzopardi J, Mahomoodally MF (2020) Stevia rebaudiana Bertoni.: an updated review of its health benefits, industrial applications and safety. Trends Food Sci Tech 100:177-189. https://doi.org/10.1016/j.tifs.2020.04.030

3. Arnold K, Bordoli L, Kopp, Schwede, T (2006) The SWISS-MODEL workspace: a web-based environment for protein structure homology modelling Bioinformatics, 22:195-201. https://doi.org/10.1093/bioinformatics/bti770

4. Bayraktar M, Naziri E, Karabey F, Akgun IH, Bedir E, Röck-Okuyucu B, Gurel A (2018) Enhancement of stevioside production by using biotechnological approach in in vitro culture of Stevia rebaudiana. International Journal of Secondary Metabolite 5:362-374. https://doi.org/10.21448/ijsm.496724

5. Brandle JE, Telmer PG (2007) Steviol glycoside biosynthesis. Phytochemistry 68:1855-1863. https://doi.org/10.1016/j.phytochem.2007.02.010

6. Buchan DW, Ward S, Lobley AE, Nugent T, Bryson K, Jones DT (2010) Protein annotation and modelling servers at University College London. Nucl. Acids Res. 38:563-568. https://doi.org/10.1093/nar/gkq427

7. Ceunen S, Geuns JMC (2013) Steviol Glycosides: Chemical Diversity, Metabolism, and Function. J. Nat. Prod 76:1201-1228. https://doi: 10.1021/np400203b 
8. Geuns, J.M.C. Stevioside. Phytochemistry,v. 64, p. 913-921, 2003.

9. Chughtai MFJ, Imran Pashab, Zahoor T, Khaliq A, Ahsan S, Wuc Z, Nadeem M, Mehmood T, Amire RM, Yasminf I, Liaqat A, Saira Tanweerh S (2020) Nutritional and therapeutic perspectives of Stevia rebaudiana as emerging sweetener; a way forward for sweetener industry. Journal of Food 18:164177. https://doi.org/10.1016/j.btre.2020.e00450

10. Gerwig GJ, Poele EM, Dijkhuizen L, Kamerling LP (2017) Structural analysis of rebaudioside A derivatives obtained by Lactobacillus reuteri 180 glucansucrase-catalyzed trans-a- glucosylation. Carbohydr. Res. 440:51-62. https://doi: 10.1016/j.carres.2017.01.008

11. Hall A (1999) Bioedit: a user friendly biological sequence alignment editor and analysis program for Windows 95/98/NT. Nucleic Acids Symp. Ser. 41:95-98.

12. Humphrey TV, Richman AS, Menassa R, Brandle JE (2006) Spatial organization of four enzymes from Stevia rebaudiana that are involved in steviol glycoside synthesis. Plant Mol. Biol. 61:47-62. https://doi.org/10.1007/s11103-005-5966-9

13. JECFA (2010) Steviol glycosides. In: Compendium of Food Additive Specifications. FAO JECFA Monographs 10:17-21.

14. Jones DT (1999) Protein secondary structure prediction based on position-specific scoring matrices. J. Mol. Biol. 292:195-202. https://doi.org/10.1006/jmbi.1999.3091

15. Kumar H, Kaul K, Bajpai-Gupta S, Kaul VK, Kumar S (2012) A comprehensive analysis of fifteen genes of steviol glycosides biosynthesis pathway in Stevia rebaudiana (Bertoni). Gene 492:276-284. https://doi:10.1016/j.gene.2011.10.015

16. Kumar S, Stecher G, Li M, Knyaz C, Tamura K (2018). MEGA X: Molecular Evolutionary Genetics Analysis across Computing Platforms. Mol. Biol. Evol. 35:1547-1549.

https://doi.org/10.1093/molbev/msy096

17. Kim MJ, Zheng J, Liao MH, Jang IC (2019) Overexpression of SrUGT76G1 in Stevia alters major steviol glycosides composition towards improved quality. Plant Biotechnol J. 17:1037-1047. https://doi.org/10.1111/pbi.13035

18. Lee SG, Salomona E, Yud O, Jeza JM (2019) Molecular basis for branched steviol glucoside biosynthesis. PNAS 116:13131-13136. https://doi.org/10.1073/pnas.1902104116

19. Lemus-Mondaca R, Vega-Gálvez A, Zura-Bravo L, Ah-Hen K (2012) Stevia rebaudiana Bertoni, source of a high-potency natural sweetener: a comprehensive review on the biochemical, nutritional and functional aspects. Food Chem. 132:1121-1132. https://doi.org/10.1016/j.foodchem.2011.11.140

20. Livak KJ, Schmittgen TD (2001) Analysis of relative gene expression data using real-time quantitative PCR and the 2(-Delta Delta C(T)) Method. Methods 25:402-408. https://doi.org/doi:10.1006/meth.2001.1262

21. Liu Z, Li J, Sun Y, Zhang P, Wang Y (2020) Structural Insights into the Catalytic Mechanism of a Plant Diterpene Glycosyltransferase SrUGT76G1. Plant Communications. 1:100004. https://doi.org/10.1016/j.xplc.2019.100004. 
22. Li W, Zhou Y, You W et al (2018) Development of Photoaffinity Probe for the Discovery of Steviol Glycosides Biosynthesis Pathway in Stevia rebaudiana and Rapid Substrate Screening. ACS Chem Biol. 13:1944-1949. https://doi.org/10.1021/acschembio8b002 85

23. Lucho SR, do Amaral MN, Milech C, Ferrer MA, Calderón AA, Bianchi VJ, Braga EJB (2018a) Elicitorinduced transcriptional changes of genes of the steviol glycosides biosynthesis pathway in Stevia rebaudiana Bertoni. J. Plant Growth Regul. 37:971-985. https://doi.org/10.1007/s00344-018-9795-x

24. Lucho SR, do Amaral, MN, Benitez LC, Milech C, Kleinowski, AM, Bianchi VJ, Braga EJB (2018b) Validation of reference genes for RT-qPCR studies in Stevia rebaudiana in response to elicitor agents. Physiol Mol Biol Plants. 24:767-779. https://doi: 10.1007/s12298-018-0583-7

25. Lucho SR, do Amaral MR, López-Orenes A, Kleinowski AM, do Amarante L, Ferrer MA, Calderón AA, Braga EJB (2019a) Plant Growth Regulators as Potential Elicitors to Increase the Contents of Phenolic Compounds and Antioxidant Capacity in Stevia Plants. Sugar Tech 21:696-702. https://doi.org/10.1007/s12355-018-0673-4

26. Lucho SR, do Amaral MR, Auller PA, Bianchi VJ, Ferrer MA, Calderón AA, Braga EJB (2019b) Salt Stress-Induced Changes in In Vitro Cultured Stevia rebaudiana Bertoni: Effect on Metabolite Contents, Antioxidant Capacity and Expression of Steviol Glycosides-Related Biosynthetic Genes. J Plant Growth Regul. 38:1341-1353. https://doi.org/10.1007/s00344-019-09937-6

27. Lucho SR, do Amaral MN, Milech C, Bianchi VJ, Almagro L, Ferrer MA, Calderón AA, Braga EJB (2021) Gibberellin reverses the negative effect of paclobutrazol but not of chlorocholine chloride on the expression of SGs/GAs biosynthesis-related genes and increases the levels of relevant metabolites in Stevia rebaudiana. Plant Cell Tiss Organ Cult 146:171-184. https://doi.org/10.1007/s11240-02102059-6

28. Madhav H, Bhasker S, Chinnamma M (2012) Functional and structural variation of uridine diphosphate glycosyltransferase (UGT) gene of Stevia rebaudiana-UGTSr involved in the synthesis of rebaudioside A. Plant Physiol. Biochem. 63:245-253.

https://doi.org/10.1016/j.plaphy.2012.11.029

29. Murashige T (1962) A Revised Medium for Rapid Growth and Bio Agsays with Tohaoco Tissue Cultures. Physiol Plant 15:473-479.

30. Olsson K, Carlsen S, Semmler A, Simón E, Mikkelsen MD, Moller BL (2016) Microbial production of next-generation stevia sweeteners. Microb Cell Fact 15:207. https://doi.org/10.1186/s12934-0160609-1

31. Petit E, Jacques A, Daydé J, Vallejo V, Berger M (2019) UGT76G1 polymorphism in Stevia rebaudiana: New variants for steviol glycosides conjugation as Revealed by Expression Analysis of Regulatory Genes and Metabolic Inhibitors Studies. Plant Physiol Biochem 135:563-569. https://doi:10.1016/j.plaphy.2018.11.002

32. Richman A, Swanson A, Humphrey T, Chapman R, Mcgarvey B, Pocs R, Brandle J (2005) Functional genomics uncovers three glucosyltransferases involved in the synthesis of the major sweet glucosides of Stevia rebaudiana. Plant J 41:56-67. https://doi:10.1111/j.1365-313X.2004.02275.x 
33. Richman AS, Gijzen M, Starratt AN, Yang Z, Brandle, JE (1999) Diterpene synthesis in Stevia rebaudiana: recruitment and up-regulation of key enzymes from the gibberellin biosynthetic pathway. The Plant Journal. 19:411-421.

34. Saifi M, Yogindran S, Nasrullah N, Nissar U, Gul I, Abdin MZ (2019) Co-expression of anti-miR319g and miRStv_11 lead to enhanced steviol glycosides content in Stevia rebaudiana. BMC Plant Biol 19:274. https://doi.org/10.1186/s12870-019-1871-2

35. Singh G, Singh G, Singh P, Parmar R, Paul N, Vashist R, Swarnkar MK, Kumar A, Singh S, Singh AK, Kumar S, Sharm RM (2017) Molecular dissection of transcriptional reprogramming of steviol glycosides synthesis in leaf tissue during developmental phase transitions in Stevia rebaudiana Bert. Sci Rep 7:1-13. https://doi:10.1038/s41598-017-12025-y

36. Tamura K, Nei M, Kumar S (2004) Prospects for inferring very large phylogenies by using the neighbor-joining method. Proceedings of the National Academy of Sciences (USA) 101:11030-11035.

37. Ullah A, Munir S, Mabkhot Y, Badshah S (2019) Bioactivity Profile of the Diterpene Isosteviol and its Derivatives. Molecules 24:678. https://doi:10.3390/molecules24040678

38. Wang J, Li S, Xiong Z, Wang Y (2016) Pathway mining-based integration of critical enzyme parts for de novo biosynthesis of steviolglycosides sweetener in Escherichia coli. Cell Res. 26:258-261. https://doi.org/10.1038/cr.2015.111

39. Yadav SK, Guleria P (2012) Steviol glycosides from Stevia: biosynthesis pathway review and their application in foods andmedicine. Crit Rev Food Sci Nutr 52:988-998. https://doi.org/10.1080/10408398.2010.519447

40. Yang Y, Huang S, Han Y, Yuan H, Gu S, Zhao Y (2014) Base substitution mutations in uridinediphosphate-dependent glycosyltransferase 76G1 gene of Stevia rebaudiana causes the low levels of rebaudioside A Mutations in UGT76G1, A key gene of steviol glycosides synthesis. Plant Physiol. Biochem. 80:220-225. https://doi.org/10.1016/j.plaphy.2014.04.005

41. Yang, T, Zhang J, Ke D, Yang W, Tang M, Jiang J, Cheng G, Li J, Wei Cheng, Wei Y, Li Q, Naismith JH, Zhu X (2019) Hydrophobic recognition allows the glycosyltransferase UGT76G1 to catalyze its substrate in two orientations. Nat Commun 10:3214. https://doi.org/10.1038/s41467-019-11154-4

42. Yücesan B, Mohammed A, Büyükgö R, Cevher Altug C, Kavas O, Gürel Se, Ekrem Gürel E (2016) In vitro and ex vitro propagation of Stevia rebaudiana Bertoni with high Rebaudioside-A content-A commercial scale application. Sci Hortic 203:20-28. https://doi.org/10.1016/j.scienta.2016.03.008

43. Zhang S, Chen H, Xiao J, Liu Q, Xiao R, Wu W (2019) Mutations in the uridine diphosphate glucosyltransferase $76 \mathrm{G} 1$ gene result in different contents of the major steviol glycosides in Stevia rebaudiana. Phytochemistry, 162:141-147. https://doi.org/10.1016/j.phytochem.2019.03.008

44. Zhang S, Liu Q, Lyu C, Chen J, Xiao R, Chen J, Yang Y, Zhang H, Hou K, Wu W (2020a) Characterizing glycosyltransferases by a combination of sequencing platforms applied to the leaf tissues of Stevia rebaudiana. BMC Genomics. 21, 794. https://doi.org/10.1186/s12864-020-07195-5

45. Zhang T, Xiaoyang X, Yuming S, Chunsun G, Menglan H, Yunxiao G, Yuan H, Yang Y (2020b) The SrWRKY71 transcription factor negatively regulates SrUGT76G1 expression in Stevia rebaudiana. 
Plant Physiol. Biochemi. 148:26-34.

46. Zhang S, Yang Y, Lyu C, Chen J, Li D, Liu Y, Zhang Z, Liu Y, Wu W (2021) Identification of the Key Residues of the Uridine Diphosphate Glycosyltransferase 91D2 and its Effect on the Accumulation of Steviol Glycosides in Stevia rebaudiana. J. Agric. Food Chem. 69:1852-1863. https://doi.org/10.1021/acs.jafc.0c07066

\section{Figures}

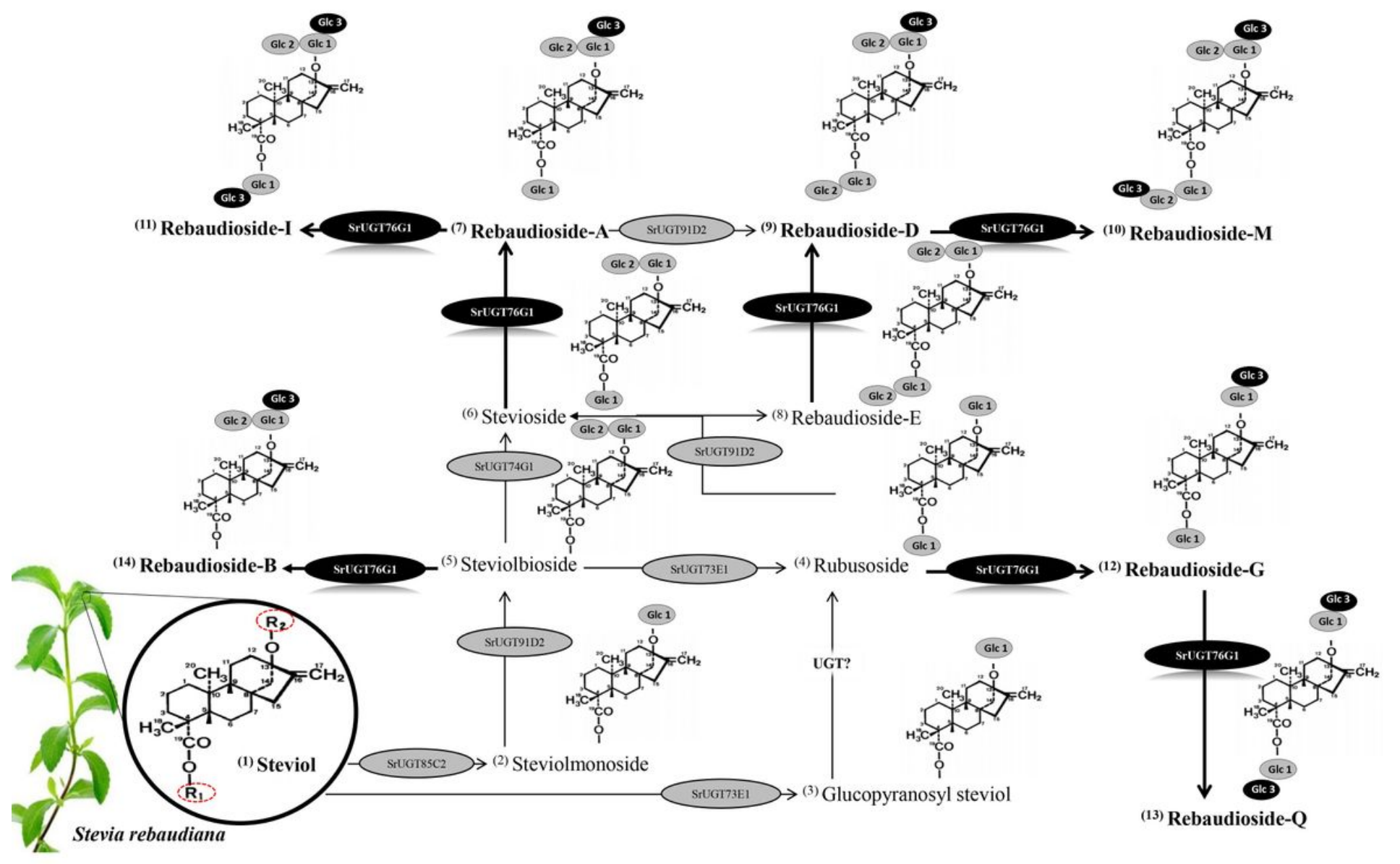

\section{Figure 1}

Simplified biosynthetic pathways of the steviol glycosides in Stevia rebaudiana from the backbone steviol. The largest arrows show reactions catalyzed by SrUGT76G1, key enzyme to this study (black ellipses) and the smallest arrows reactions catalyzed by other SrUGTs (gray ellipses). The products of each reaction, with one or more glucose molecules attached to the core steviol backbone at R1 and R2 positions, are also shown. *(1-15) Reference number in text. 


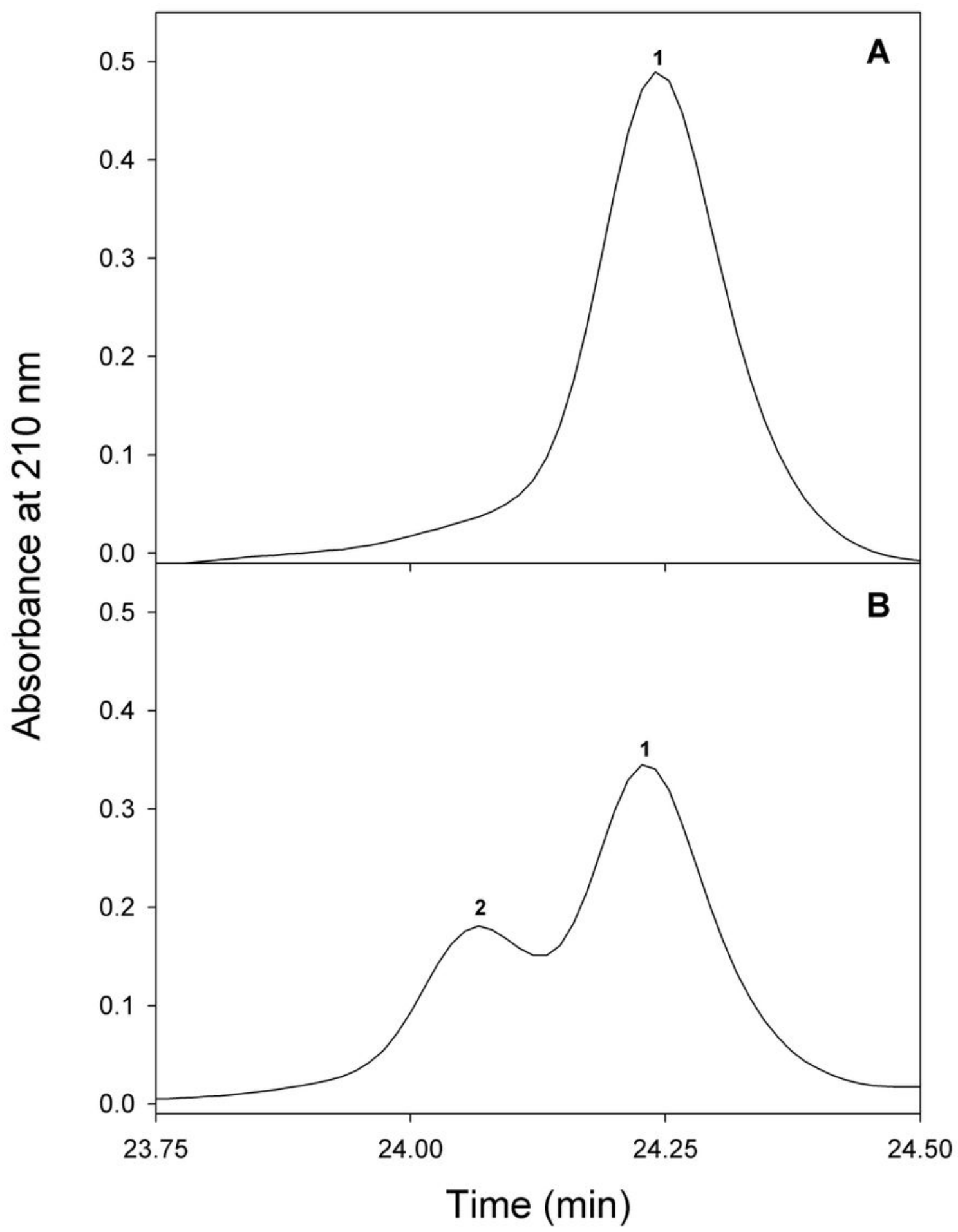

Figure 2

Chromatograms at $210 \mathrm{~nm}$ of reaction media containing partially purified protein fractions obtained from Brazil (A) and Spain (B) stevia plants. 1, stevioside; 2, rebaudioside-A. 


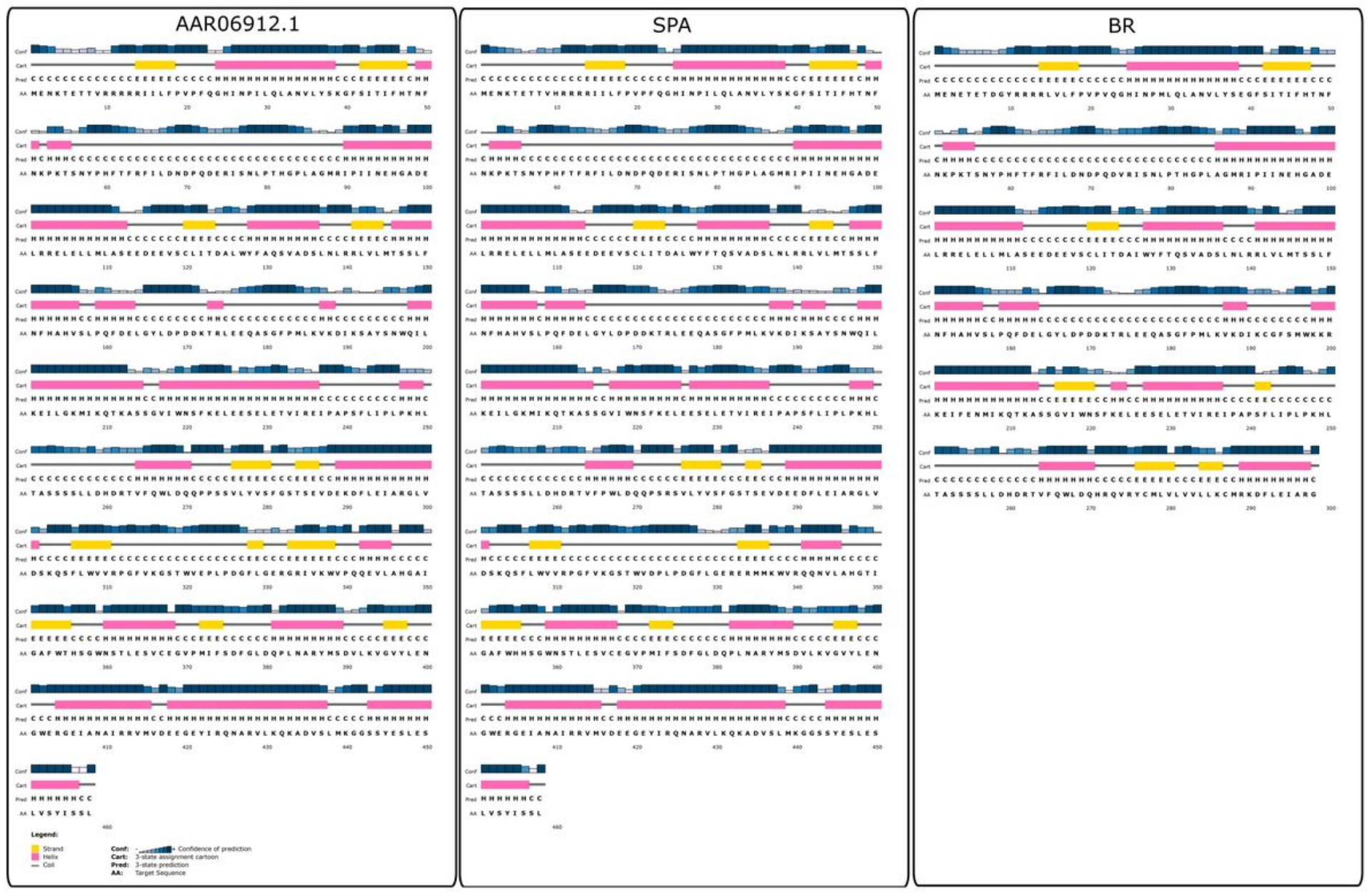

Figure 3

The predicted secondary structure of SrUGT76G1. Left diagram shows Reference (GenBank Accession no. AAR06912.1); the middle and right diagrams show stevia samples from Spain and Brazil, respectively. 


\begin{tabular}{|c|c|c|}
\hline AAR0 6912.1 & 1 & MENKTETTVRRRRRI I LFPVPFQGH INP I LQLANVLYSKGFS I T I FHTNF \\
\hline SPA & 1 & MENKTETTVHRRRR I I LFPVPFQGH INP I LQLANVLYSKGFS I T I EHTNE \\
\hline BR & 1 & MENETETDGYRRRRLVLFPVPVQGH INPMLQLANVLYSEGFS I T I FHTNE \\
\hline AAR0 6912.1 & 51 & NKPKTSNYPHFTFRF I LDNDPQDER ISNLPTHGPLAGMR I P I INEHGADE \\
\hline SPA & 51 & NKPKTSNYPHFTFRF I LDNDPQDER ISNLPTHGPLAGMRIP I INEHGADE \\
\hline BR & 51 & NKPKTSNYPHFTFRF ILDNDPQDVRISNLPTHGPLAGMR I P I INEHGADE \\
\hline AAR0 6912.1 & 101 & LRRELELLMLASEEDEEVSCLITDALWYFAQSVADSLNLRRLVLMTSSL \\
\hline SPA & 101 & LRRELELLMLASEEDEEVSCLITDALWYETQSVADSLNLRRLVLMTSSLF \\
\hline BR & 101 & LRRELELLMLASEEDEEVSCLITDAIWYFTQSVADSLNLRRLVLMTSSLF \\
\hline AAR0 6912.1 & 151 & NFHAHVSLPQFDELGYLDPDDKTRLEEQASGFPMLKVKDIKSAYSNWQ \\
\hline SPA & 151 & NFHAHVSLPQFDELGYLDPDDKTRLEEQASGFPMLKVKDIKSAYSNWQIL \\
\hline BR & 151 & NFHAHVSLPQFDELGYLDPDDKTRLEEQASGFPMLKVKDIKCGFSMWKK \\
\hline AAR0 6912.1 & 201 & KEILGKMIKQTKASSGVIWNSFKELEESELETVIREIPAPSFLIPLPKH \\
\hline SPA & 201 & KEILGKMIKQTKASSGVIWNSFKELEESELETVIREIPAPSFLIPLPKHL \\
\hline BR & 201 & KEIFENMIKQTKASSGVIWNSFKELEESELETVIREIPAPSFLIPLPKHL \\
\hline AAR0 6912.1 & 251 & TASSSSLLDHDRTVFQWLDQQPPSSVLYVSFGSTSEVDEKDFLEIARGI \\
\hline SPA & 251 & TASSSSLLDHDRTVFPWLDQQPSRSVLYVSFGSTSEVDEEDFLEIARGLV \\
\hline BR & 251 & TASSSSLLDHDRTVFQWLDQHRQVRYCMLVLVVLLKCMRKDFLEIARG* $\bar{D}$ \\
\hline AAR0 6912.1 & 301 & DSKQSFL---WVVRPGFVKGSTWVEPLPDGFLGERGRIVKWVPQQEVI \\
\hline SPA & 301 & DSKQSFL---WVVRPGFVKGSTWVDPLPDGF LGERERMMKWVRQQNVLAH \\
\hline BR & 301 & DSKAAVLSGGLDLRSALRDCERGLRTVARLEMHRVDSKEGIAEIEIRLQH \\
\hline AAR0 6912.1 & 348 & GAIGAFWTHSGWNSTLESVCEGVPMIFSDFGLDQPLNARYMSDVLKVG \\
\hline SPA & 348 & GTI GAFWHHSGWNSTLESVCEGVPMIFSDFGLDQPLNARYMSDVLKVGVY \\
\hline BR & 348 & --VANFLQSMQAGNSLESVCEGVPMIFSDFGLDQPLNARYMSDVLKVGVY \\
\hline AAR0 6912.1 & 398 & LENGWERGEIANAIRRVMVDEEGEYIRQNARVLKQKADVSLMKGGSSY \\
\hline SPA & 398 & LENGWERGE IANA IRRVMVDEEGEY IRQNARVLKQKADVSLMKGGSSYES \\
\hline BR & 398 & LENGWERGEIANAIRRVMVDEEGEY IRQNARVLKQKADVSLMKGGSSYES \\
\hline AAR0 6912.1 & 448 & LESLVSYISSL \\
\hline SPA & 448 & LESLVSYISSL \\
\hline BR & 448 & LESLVSYISSL \\
\hline
\end{tabular}

\section{Figure 4}

Multiple sequence alignment of SrUGT76G1 genes showing their similarity. The sequences with black background indicate the completely identical residues and the sequences with white background indicate the divergent residues (mutations). In red detail, *stop premature codon and in red rectangle, change of key amino acid residues. Red dotted box, PSPG (putative secondary plant glycosyltransferase). 

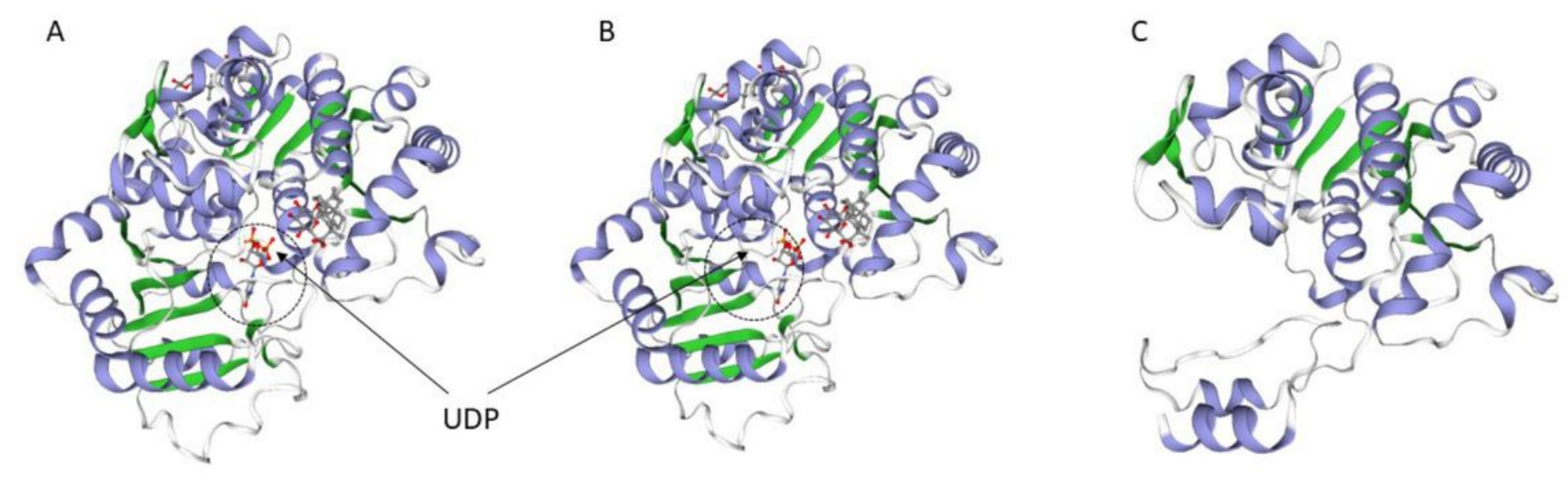

\section{Figure 5}

Three-dimensional structure of SrUGT76G1 in Reference, accession number AY345974.1 (A), Spain (B), and (C) Brazil.

(A)

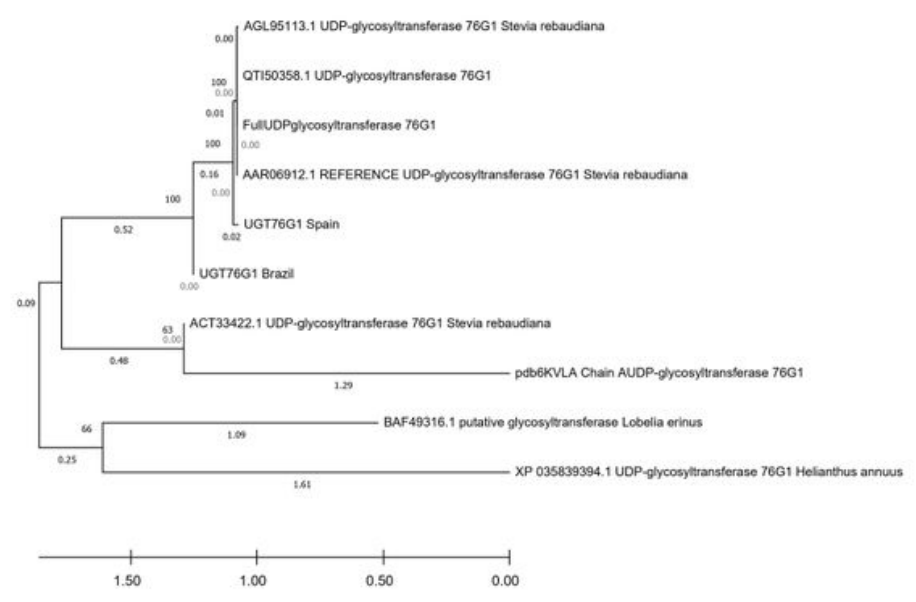

(B)

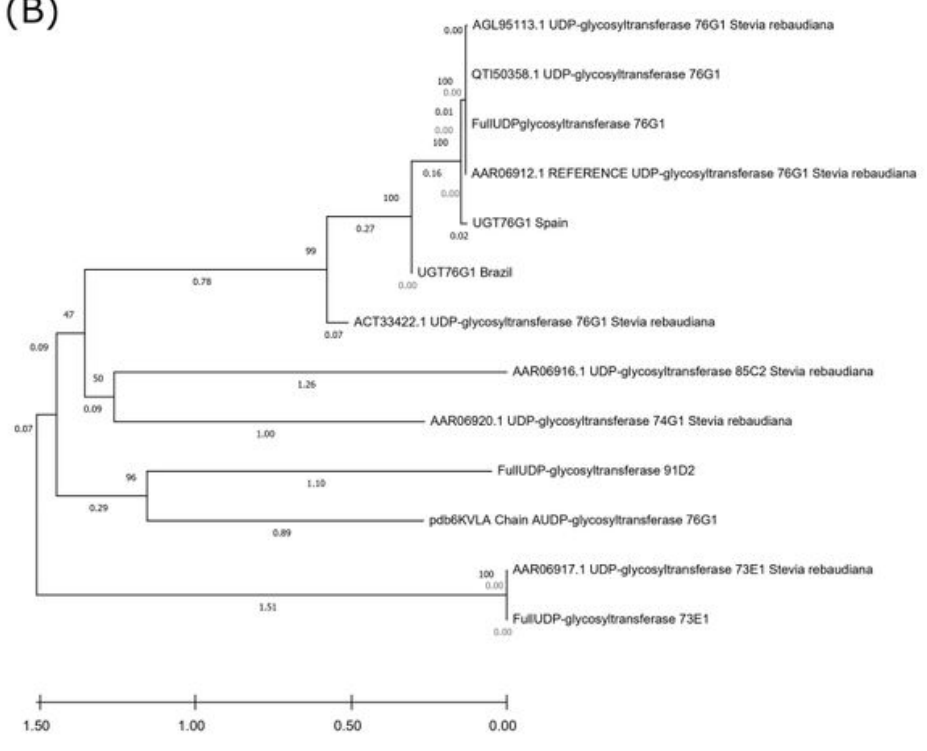

Figure 6

Phylogenetic analysis of UGT-related proteins in stevia. (A) Neighbor-joining phylogenetic tree of SrUGT76G1 and two others species and (B) all SrUGTs identified proteins.

\section{Supplementary Files}

This is a list of supplementary files associated with this preprint. Click to download. 
- Graphicalabstract.pdf

- SupplementarymaterialFigure1.pdf

- SupplementarymaterialFigure2.pdf

- SupplementarymaterialTable1.docx

- SupplementarymaterialTable2.docx 